\title{
Anionic surfactant sulfate dodecyl sodium (SDS)-induced thermodynamics and conformational changes of collagen by ultrasensitive microcalorimetry
}

\author{
Jie Zhang ${ }^{1}$, Chunhua Wang ${ }^{1,2^{*}}$, Fengteng Zhang ${ }^{1}$ and Wei Lin ${ }^{1,2^{*}}$ (1)
}

\begin{abstract}
In this communication, sulfate dodecyl sodium (SDS)-induced thermodynamics and conformational changes of collagen were studied. We used ultrasensitive differential scanning calorimetry (US-DSC) to directly monitor the thermal transition of collagen in the presence of SDS. The results show that SDS affects the conformation and thermal stability of collagen very differently depending on its concentrations. At $C_{S D S} \leq 0.05 \mathrm{mM}$, the enhanced thermal stability of collagen indicates the stabilizing effect by SDS. However, a further increase of SDS leads to the denaturation of collagen, verifying the wellknown ability of SDS to unfold proteins. This striking difference in thermodynamics and conformational changes of collagen caused by SDS concentrations can be explained in terms of their interactions. With increasing SDS, the binding of SDS to collagen can be dominated by electrostatic interaction shifting to hydrophobic interaction, and the latter plays a key role in loosening and unfolding the triple-helix structure of collagen. The important finding in the present study is the stabilizing effect of SDS on collagen molecules at extreme low concentration.
\end{abstract}

Keywords: Collagen, Sodium dodecyl sulfate, Conformational change, Microcalorimetry

\section{Introduction}

The interaction between protein and surfactant is of significant importance in many fields, such as sanitary [1], drugs [2], food [3], biomedical engineering [4] and so on. In fact, the early application of surfactant can date back to $2200 \mathrm{BC}$ when soap was first used to remove protein-rich dirt [5]. Another important and practical application of surfactants where the knowledge of interaction between protein and surfactant plays a vital role is in bio-separation and bioanalytical methods [6]. For instance, protein purification can be achieved by surfactants due to their strong interactions [7]. Moreover, surfactants are often used as denaturants for the studies on protein self-assembly and stability [8] and also

\footnotetext{
* Correspondence: wangchunhua@scu.edu.cn; wlin@scu.edu.cn

'Department of Biomass and Leather Engineering, Key Laboratory of Leather Chemistry and Engineering of Ministry of Education, Sichuan University, Chengdu 610065, China

Full list of author information is available at the end of the article
}

as probe molecules to investigate structures and functions of proteins $[9,10]$.

Collagen, derived from livestock skins or bones, is the most abundant connective tissue protein and has been widely used in cosmetics [11], biomedicine [12], health food [13] and leather industry [14]. These industrial applications of collagen inevitably involve the use of surfactants to achieve required functions. Especially in the cosmetics industry, the surfactants are commonly applied in cosmetic emulsions based on collagen for the purpose of good solubility, rheological properties and colloid stability [15]. Also, it was reported that surfactants sodium dodecyl sulphate (SDS) can be used to weaken both the electrostatic and the hydrophobic interactions during collagen fibrillogenesis in vitro [16]. Therefore, studies on the collagen-surfactants systems have attracted much interest as understanding the underlying mechanism is helpful to promote their application. The first study on this topic was 
described by Mandal et al. [17] in 1987. They found that the presence of ionic and nonionic surfactant would cause the decreased intrinsic viscosity of collagen solutions. $\mathrm{Du}$ et al. [18] found that the fluorescence intensity of collagen solutions varied with the types of surfactants. Recent studies by Kezwon et al. [19, 20] involved the effect of surfactants on surface properties of collagen by combination of spectroscopic techniques, calorimetry, and axisymmetric drop shape analysis. Their results demonstrated that the changes of surface activity and rheological properties of collagen solutions depended on the types of surfactants. Despite the related studies on physical and chemical properties of collagen-surfactant solutions, limited information focusing on the interaction between surfactants and collagen has been reported till now [21-23]. More importantly, the knowledge of the structural and conformational changes of collagen induced by surfactants has remained unclear, which is not only essential to understand the interaction of collagen-surfactant at the molecular level but also of great significance for their practical use as it is directly related to its functional and bioactive properties.

In recent years, the development of modern testing technologies including microcalorimetry, small angle scattering technique (SAXS) [24], cryogenic-transmission electron microscopy (cryo-TEM) [25] has made it possible to study the protein-surfactant interaction at the molecular level. Among them, ultrasensitive differential scanning calorimetry (US-DSC) has emerged as a powerful tool to explore the structure and denaturation process of proteins because it is accepted as the most sensitive differential scanning calorimeter so far, with an accuracy of $0.02 \mu \mathrm{cal} /$ $\mathrm{s}[26,27]$. It can be used to directly measure calorimetric enthalpy change $(\Delta H)$, the thermal transition temperature $\left(T_{\mathrm{m}}\right)$ and specific heat capacity $\left(C_{\mathrm{p}}\right)$ during the unfolding of triple-helix to random coils for collagen in dilute aqueous solution, and provide valuable information regarding the minor conformational change of collagen triggered by other small molecules [28].

In this paper, US-DSC were used to investigate the effect of anionic surfactant (SDS) on the thermal stability of collagen in solutions; and the induced conformational change of collagen as well as the interactions between them were discussed. It is well known that the interactions between surfactants and proteins involve very complex processes [29]. The changes of three-dimensional structure of proteins induced by surfactants are closely related to surfactants types and concentrations [18-20]. Herein, collagenSDS system is of particular interest because collagen is a well-characterized protein with obvious conformational heat and SDS is a representative of anionic surfactants with appropriate charge density and hydrophobic chain [21]. In addition, SDS interacts more strongly with most proteins compared with cationic surfactants [29]. To our best knowledge, using US-DSC to study the conformational structure change of collagen as a function of SDS concentration has not been reported yet. Our study can provide insightful information relevant to theoretical study of proteins-surfactants interaction and their applications.

\section{Experimental section}

\subsection{Materials}

The acid soluble collagen used in this study was extracted from the fresh adult bovine Achilles tendon according to the procedure reported in our previous study [30]. Sodium dodecyl sulfate (SDS) was purchased by the Kelong Reagent Company (Chengdu, China). All chemical reagents used in this work were of analytical grade. The deionized water used in the experiment was purified with a UP Water Purification System (Chengdu, China). All collagen samples were freshly prepared just before use.

\subsection{Sample preparation}

Collagen solutions and SDS solutions were freshly prepared with acetic acid $(0.5 \mathrm{M}, \mathrm{pH} 2.5)$, respectively. Equal volumes of collagen solutions and corresponding SDS solutions were mixed uniformly to get homogeneous solutions. The final concentration of collagen was $0.5 \mathrm{mg} /$ $\mathrm{mL}$ for the US-DSC measurements.

\subsection{Ultra-sensitive differential scanning calorimeter (US-DSC) measurements}

Collagen solutions $(0.5 \mathrm{mg} / \mathrm{mL})$ with varied concentrations of SDS was prepared in acetic acid and kept at $4{ }^{\circ} \mathrm{C}$ for $12 \mathrm{~h}$ before the tests. The solutions were measured on a USDSC microcalorimeter (Microcal US DSC, Marvin, UK) with the matching solution (acetic acid, $0.5 \mathrm{M}$ ) as the reference, the concentrations of SDS ranged from 0 to $0.09 \mathrm{mM}$.

Baseline controls were obtained with corresponding acetic acid solutions in both sample and reference cell, and subtracted from the sample runs. The sample solution and the reference solution were degassed for $30 \mathrm{~min}$ at ambient temperature $\left(25^{\circ} \mathrm{C}\right)$ before tests. All of the scans were conducted from 20 to $60^{\circ} \mathrm{C}$ at $1{ }^{\circ} \mathrm{C} / \mathrm{min}$. The calorimetric enthalpy change $(\Delta H)$ was calculated from the area under each peak. The melting temperature $(T \mathrm{~m})$ was taken as the maximum usually centered at the transition.

\section{The interaction between SDS and collagen by microcalorimetry}

Fig. $1 \mathrm{~A}$ and $\mathrm{A}_{1}$ shows the temperature dependence of the specific heat capacity $\left(C_{\mathrm{p}}\right)$ and transition temperature $\left(T_{\mathrm{m}}\right)$ of Type I collagen in $0.5 \mathrm{M}$ acetate buffer $\left(C_{\text {collagen }}=\right.$ $0.5 \mathrm{mg} / \mathrm{mL})$ with very low concentration of SDS $\left(C_{\mathrm{SDS}}=\right.$ 0.01-0.05 mM), respectively. As previously reported [31], the thermal denaturation process of collagen solution demonstrates a bimodal transition with a pre-transition at $33^{\circ} \mathrm{C}\left(T_{\mathrm{m} 1}\right)$ and the major transition at $41^{\circ} \mathrm{C}\left(T_{\mathrm{m} 2}\right)$. The corresponding enthalpy changes $\left(\Delta H_{1}, \Delta H_{2}\right)$ of the 

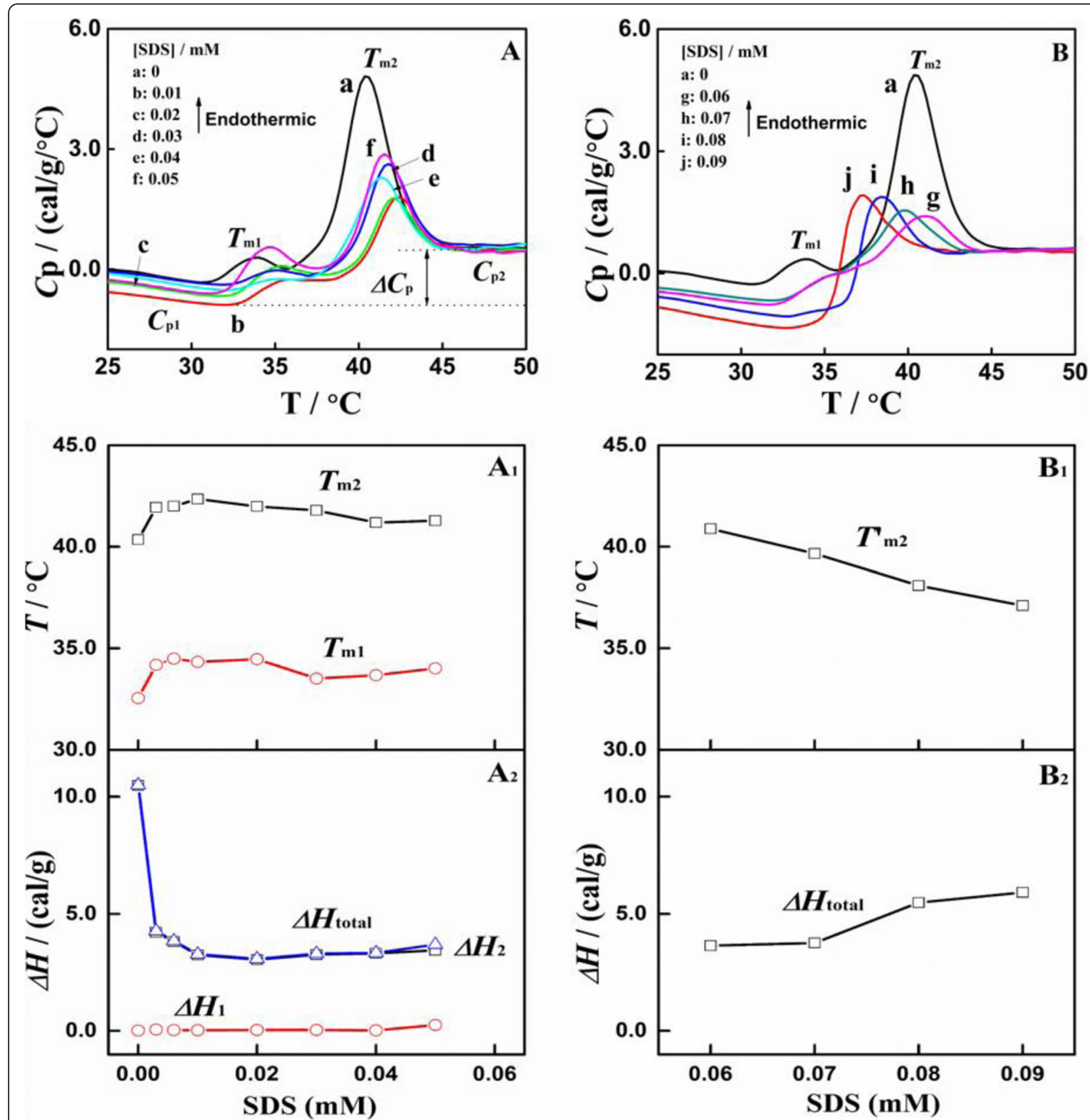

Fig. 1 The specific heat capacity $\left(C_{p}\right)(\mathbf{A}, \mathbf{B})$, thermal transition temperature $\left(T_{m}\right)\left(A_{1}, B_{1}\right)$ and enthalpy change $(\Delta H)\left(A_{2}, B_{2}\right)$ of type I collagen in $0.5 \mathrm{M}$ acetic acid $(\mathrm{pH} 2.5)$ in the presence of SDS $\left(\mathrm{C}_{\mathrm{SDS}}=0.01 \sim 0.09 \mathrm{mM}\right)$ with different concentrations

bimodal transition and total enthalpy change $\left(\Delta H_{\text {total }}\right)$ is shown in Fig. $1 \mathrm{~A}_{2}$.

It is commonly accepted that the interaction between proteins and SDS are mainly electrostatic and hydrophobic interactions, always resulting in the formation of SDSprotein complex [19]. Besides, many studies further proposed that the binding of SDS with proteins including collagen takes place in two distinct stages [21, 32]. In the first stage, the binding proceeds on the base of electrostatic interaction between the sulfate anion of SDS and the positively charged side chains of protein, along with a hydrophobic interaction between the dodecyl chain of SDS and nonpolar regions of the protein surface adjacent to its cationic sites [33]. The second stage of binding is cooperative binding, during which the protein unfolds to expose its hydrophobic interior, thereby promoting potential binding. Namely, the process involves a combination of electrostatic interaction and non-specific hydrophobic interaction. The 
latter plays the decisive and dominated roles [34] and has a tendency to hydrophilize proteins surface, thus rendering the complex more hydrophilic than the original proteins $[19,34]$.

In our experiments (Fig. $1 \mathrm{~A}-\mathrm{A}_{2}$ ), after the addition of slight SDS, the bimodal feature still exists but both peak positions $\left(T_{\mathrm{m}}\right)$ slightly shift to higher temperatures. Meanwhile, a distinct decrease of $C_{\mathrm{p} 1}$ (Fig. $1 \mathrm{~A}$ ), $\Delta H_{2}$ and in turn $\Delta H_{\text {total }}$ (Fig. $1 \mathrm{~A}_{2}$ ) can be seen in comparison with those of original collagen. It is known that the $C_{\mathrm{p}}$ represents the hydrophobicity of the macromolecules, and lower $C_{\mathrm{p}}$ value means stronger hydrophilicity $[26,35]$. The enthalpy change $(\Delta H)$ concerning the transition is defined by the energy required for the destruction of the hydrogen bonds which maintain the triple-helix conformation of collagen $[26,36]$. The results shown in Fig. $1 \mathrm{~A}-\mathrm{A}_{2}$ proved that the introduction of SDS leads to the formation of SDS-collagen complex as reflected in enhanced $T_{\mathrm{m}}$, which occurs at the cost of breaking partial hydrogen bonds of collagen molecules and confers collagen increased hydrophilicity meanwhile.

It is well known that SDS possesses the ability to unfold and denature proteins. In case of collagen, denaturation process involves unfolding the triple-helix with formation of random coils, which can be commonly monitored by DSC. Kezwon et al. investigated the effect of SDS on the thermal stability of collagen solution using a Nano-DSC [19]. Their results show that the excessive addition of SDS $\left(C_{\mathrm{SDS}}=\right.$ $10^{-4} \mathrm{~mol} / \mathrm{L}$ ) does not alter the parameter values of thermal transition during collagen denaturation, and even the formation of SDS-collagen complex does not contribute to the stabilization of neither helical nor unfolded forms. Whereas in our present study, a relatively apparent increase in transition temperature of collagen $\left(\sim 2.0^{\circ} \mathrm{C}\right)$ is clearly observed in the extremely dilute $\mathrm{SDS}$ solution $\left(\mathrm{C}_{\mathrm{SDS}}=0.01 \mathrm{mM}\right.$, i.e. $10^{-5} \mathrm{~mol} / \mathrm{L}$ ). A reason for the difference with Kezwon studies is probably attributed to the higher accuracy of US-DSC used in this study than conventional DSC analysis. Our finding by US-DSC confirms that the binding of a small amount of SDS benefits to the stabilization of collage-SDS complex to some extent due to its increased hydrophilicity. Furthermore, the binding process of SDS possibly causes a release of bound water molecules upon interactions of the surfactant to collagen or rearrangement of collagen molecules, thus leading to the loss of partial hydrogen bonds of collagen [19], as reflected in the decreased $\Delta H$. To be more specific, the likely inter-ionic binding sites of SDS (namely electrostatic interaction) with collagen may locate near the positively charged amino acid residues (such as Arg and Lys) within regions of high net positive charge at $\mathrm{pH} 2.5$ (under isoelectric point of collagen, pI 7) [37].

It is worthy to note that when $\mathrm{C}_{\mathrm{SDS}}$ increases from 0.01 to $0.05 \mathrm{mM}$, the $T_{\mathrm{m}}$ of collagen shows a negligible descent $\left(<1^{\circ} \mathrm{C}\right)$, but still higher than that of original collagen. This may be due to the fact that as SDS concentration increases, both electrostatic and hydrophobic interactions increase gradually. Consequently, the stabilizing electrostatic interactions within the inner chains of collagen triple-helix itself (mainly Gly-Lys-Asp and Gly-Arg-Asp) are relatively weaker [38] and some regions of collagen maybe become loose and unstable, thus leading to slightly reduced thermal stability.

Fig. $1 \mathrm{~B}-\mathrm{B}_{2}$ shows the temperature dependence of $C_{\mathrm{p}}, T_{\mathrm{m}}$ and $\Delta H$ of collagen in $0.5 \mathrm{M}$ acetate buffer with SDS ranging from 0.06 to $0.09 \mathrm{mM}$. Compared to the collagen with lower $\mathrm{C}_{\mathrm{SDS}}$ (Fig. $1 \mathrm{~A}-\mathrm{A}_{2}$ ), the bimodal transition of collagen with higher $C_{S D S}$ (above $0.06 \mathrm{mM}$ ) exhibit a very different trend. The shifting of major transition peak to lower temperature, as well as the merging of pre-transition peak into the major one, confirm that SDS can destroy the triple-helix structure to some degree at a concentration of more than $0.06 \mathrm{mM}$. The pre-transformation peak of collagen is caused by the region lacking hydroxyproline [28], which is a heat-sensitive region with unstable structure. Therefore, the pre-transformation peak cannot be distinguished as the domain of triple-helix was loosened.

As shown in Fig. $1 \mathrm{~B}_{1}$, the $T_{\mathrm{m}}$ of collagen decreases almost linearly with increasing SDS when $\mathrm{C}_{\mathrm{SDS}}$ is above 0.06 $\mathrm{mM}$, indicating that the presence of higher concentration of SDS significantly reduces the thermal stability of collagen; namely, the denaturation of collagen occurs. Also, the corresponding $C_{\mathrm{p} 1}$ values decreases accordingly, suggesting that the higher the SDS concentration, the more hydrophilic the collagen (actually collage-SDS complex) surface is. The measured results are completely different from metal-ions induced collagen denaturation process, where the $C_{\mathrm{p}}$ or surface hydrophilicity of collagen would never increase [26]. As mentioned above, a hydrophilisation of SDS-collagen complex is caused by hydrophobic interactions [34]. Therefore, herein the continuous decrease of $C_{\mathrm{p} 1}$ strongly proves that the hydrophobic interactions between collagen and SDS play a key role in denaturing collagen under sufficient SDS. It is worthy to note that $\Delta H$ of collagen increases slightly at $\mathrm{C}_{\mathrm{SDS}}$ ranging from 0.07 to $0.09 \mathrm{mM}$. This finding is unexpected and suggests that some new hydrogen bonds are likely formed during the unfolding process in the presence of SDS. The reason for this is not clear but it may be related to the aggregated peptide chains of collage triggered by SDS. In addition, another possible explanation for the increased $\Delta H$ may be the potential but neglected hydrogen-bonding between the sulfate oxygen of SDS and the nitrogen groups of the peptide segments from partial denatured collagen [39]. Noted that Further increasing SDS $(>0.09 \mathrm{mM})$, apparent fiberlike aggregates appeared and therefore no thermodynamics data can be obtained.

The interactions of SDS with collagen molecule and the resulting conformational changes as a function of SDS concentration are presented in Fig. 2. With increasing 
(B)

(c)

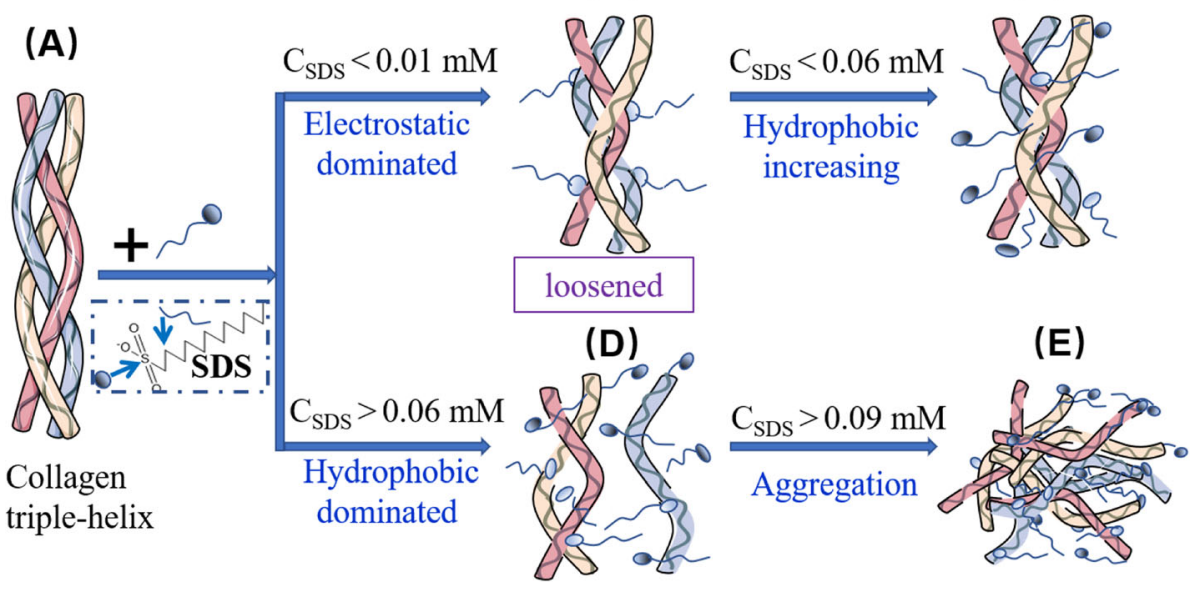

Fig. 2 Schematic of interactions between collagen molecules and anionic surfactant sulfate dodecyl sodium (SDS): (A) native triple-helix of collagen; (B) and (C): loosened structure of collagen molecule; (D) and (E): unfolding of collagen triple-helix

SDS, all the specific ionic sites in the protein structure those are capable of interacting with the surfactant are gradually saturated; the binding is subsequently dominated by hydrophobic interaction instead of electrostatic interaction under scant SDS. The difference is that electrostatic interaction as a dominant factor makes the chain structure loosened more or less (Fig. 2 $\mathrm{B}$ and $\mathrm{C}$ ), while dominant hydrophobic effect leads to the unfolding of collagen trple-helix (Fig. $2 \mathrm{D}$ and E). Moreover, at low $\mathrm{C}_{\mathrm{SDS}}$ in the range of $0.01-0.05 \mathrm{mM}$, the formed hydrophilic collagen-SDS complex can delay the hydrothermal denaturation of collagen to some extent. As a matter of fact, our finding of stabilizing effect on collagen by low concentration of SDS coincides with studies of other proteins such as keratin [33] and casein [40] and whey protein [41].

\section{Conclusions and future perspectives}

In conclusion, sulfate dodecyl sodium (SDS)-induced thermodynamics and conformational changes of collagen in dilute solution has been studied by US-DSC, and the interaction between them is the $\mathrm{C}_{\mathrm{SDS}}$ dependent. When $\mathrm{C}_{\mathrm{SDS}}$ is $\leq 0.05 \mathrm{mM}$, the collagen presents a slightly higher $T_{\mathrm{m}}\left(\sim 2^{\circ} \mathrm{C}\right)$, confirming the stabilizing effect of SDS on collagen. It can be attributed to the formation of hydrophilic SDS-collagen complex in which electrostatic interaction is a dominant factor. Whereas, as SDS increases ( $>0.06 \mathrm{mM}$ ), the obvious decrease of $T_{\mathrm{m}}$ and disappearance of transition peak reveal the unfolding of collagen due to dominant hydrophobic effect. The conformational change of collagen in the presence of SDS, especially the intermediate loose structure of collagen before unfolding/denaturation is demonstrated with US-DSC for the first time.

\section{Acknowledgements}

The authors gratefully acknowledge Wang Zhonghui from The College of Biomass Science and Engineering of Sichuan University for her great help in US-DSC measurement and characterization.

\section{Authors' contributions}

Jie Zhang was a major contributor in performing all the tests of collagen samples. Chunhua Wang designed the experiments and wrote the manuscript. Fengteng Zhang analyzed and interpreted the data regarding the structure of collagen. Wei Lin proposed the scientific idea, the methods used in this study. All authors read and approved the final manuscript.

\section{Funding}

The financial support of National Natural Science Foundation (NNSF) of China (21978177), the National Key R\&D Program of China

(2019YFC1904500), International Science and Technology Innovation Cooperation project of Sichuan Province (2020YFH0081) is gratefully acknowledged.

\section{Availability of data and materials}

All data generated or analysed during this study are included in this published article.

\section{Declarations}

\section{Competing interests}

The authors declare that they have no competing interests.

\section{Author details}

'Department of Biomass and Leather Engineering, Key Laboratory of Leather Chemistry and Engineering of Ministry of Education, Sichuan University, Chengdu 610065, China. ${ }^{2}$ National Engineering Research Center of Clean Technology in Leather Industry, Sichuan University, Chengdu 610065, China.

Received: 2 March 2021 Accepted: 30 May 2021

Published online: 15 August 2021

\section{References}

1. Lund H, Kaasgaard SG, Skagerlind P, Jorgensen L, Jorgensen Cl, van de Weert M. Correlation between enzyme activity and stability of a protease, an alpha-amylase and a lipase in a simplified liquid laundry detergent system, determined by differential scanning calorimetry. J Surfactant Deterg. 2012;15(1):9-21. https://doi.org/10.1007/s11743-011-1272-5. 
2. Lee HJ, McAuley A, Schilke KF, McGuire J. Molecular origins of surfactantmediated stabilization of protein drugs. Adv Drug Deliv Rev. 2011;63(13): 1160-71. https://doi.org/10.1016/j.addr.2011.06.015.

3. Hansted JG, Wejse PL, Bertelsen H, Otzen DE. Effect of protein-surfactant interactions on aggregation of beta-lactoglobulin. BBA-Proteins Proteomics. 2011;1814(5):713-23. https://doi.org/10.1016/j.bbapap.2011.03.011.

4. del Castillo-Santaella T, Peula-Garcia JM, Maldonado-Valderrama J, et al. Interaction of surfactant and protein at the O/W interface and its effect on colloidal and biological properties of polymeric nanocarriers. Colloid Surf B-Biointerfaces. 2019;173:295-302. https://doi.org/10.1016/j.colsurfb.2 018.09.072.

5. Otzen D. Protein-surfactant interactions: a tale of many states. BBAProteins Proteomics. 2011;1814(5):562-91. https://doi.org/10.1016/j.bbapa p.2011.03.003

6. Shapiro AL, Vinuela E, Maizel JV. Molecular weight estimation of polypeptide chains by electrophoresis in sds-polyacrylamide gels. Biochem Biophys Res Commun. 1967;28(5):815-20. https://doi.org/10.1016/0006-291x(67)90391-9.

7. Wong FWF, Ariff AB, Stuckey DC. A biocompatible surfactant, methyl ester sulphonate (MES), as a precipitating ligand for protein purification. Biochem Eng J. 2017;117:30-40. https://doi.org/10.1016/j.bej.2016.09.020.

8. Chakraborty T, Chakraborty I, Moulik SP, Ghosh S. Physicochemical and conformational studies on BSA-surfactant interaction in aqueous medium. Langmuir. 2009;25(5):3062-74. https://doi.org/10.1021/la803797x.

9. Turro NJ, Lei XG, Ananthapadmanabhan KP, Aronson M. Spectroscopic probe analysis of protein-surfactant interactions: the BSA/SDS system. Langmuir. 1995;11(7):2525-33. https://doi.org/10.1021/la00007a035.

10. Ghosh S, Banerjee AJB. A multitechnique approach in protein/surfactant interaction study: physicochemical aspects of sodium dodecyl sulfate in the presence of trypsin in aqueous medium. Biomacromolecules. 2002;3(1):9-16. https://doi.org/10.1021/bm005644d.

11. Rodriguez MIA, Barroso LGR, Sanchez ML. Collagen: a review on its sources and potential cosmetic applications. J Cosmet Dermatol. 2018;17(1):20-6. https://doi.org/10.1111/jocd.12450.

12. Lin $\mathrm{KL}$, Zhang DW, Macedo $\mathrm{MH}$, et al. Advanced collagen-based biomaterials for regenerative biomedicine. Adv Funct Mater. 2019;29(3). https://doi.org/10.1002/adfm.201804943.

13. Pal GK, Suresh PV. Sustainable valorisation of seafood by-products: recovery of collagen and development of collagen-based novel functional food ingredients. Innov Food Sci Emerg Technol. 2016;37:201-15. https://doi. org/10.1016/j.ifset.2016.03.015.

14. Covington AD. Modern tanning chemistry. Chem Soc Rev. 1997;26(2):11126. https://doi.org/10.1039/cs9972600111.

15. Fathima NN, Dhathathreyan A. Effect of surfactants on the thermal, conformational and rheological properties of collagen. Int J Biol Macromol. 2009;45(3):274-8. https://doi.org/10.1016/j.ijbiomac.2009.06.003.

16. Dombi GW, Halsall HB. Collagen fibril formation in the presence of sodium dodecyl-sulfate. Biochem J. 1985;228(3):551-6. https://doi.org/1 $0.1042 /$ bj2280551

17. Mandal AB, Ramesh DV, Dhar SC, et al. Physico-chemical studies of micelle formation on sepia cartilage collagen solutions in acetate buffer and its interaction with ionic and nonionic micelles : hydrodynamic and thermodynamic studies. Eur J Biochem. 1987;169(3):617-28. https://doi.org/1 0.1111/j.1432-1033.1987.tb13653.x

18. Du JH, Xie Q, Zeng X. Fluorometric properties of collagen protein-curcumin reacted with different surfactants. West Leather. 2009;21:18-20.

19. Kezwon A, Goral I, Fraczyk T, et al. Effect of surfactants on surface activity and rheological properties of type I collagen at air/water interface. Colloid Surf B-Biointerfaces. 2016;148:238-48. https://doi.org/1 0.1016/j.colsurfb.2016.08.058.

20. Kezwon A, Wojciechowski K. Collagen-surfactant mixtures at fluid/fluid interfaces. Colloid Surf A-Physicochem Eng Asp. 2016;509:390-400. https:// doi.org/10.1016/j.colsurfa.2016.09.040.

21. Henriquez M, Lissi E, Abuin E, Ciferri A. Assembly of amphiphilic compounds and rigid polymers .1. interaction of sodium dodecyl-sulfate with collagen. Macromolecules. 1994;27(23):6834-40. https://doi.org/10.1021/ma00101a023.

22. Krejčí J. Interaction of mixture of anionic surfactants with collagen. Int J Cosmet Sci. 2007;29(2):121-9. https://doi.org/10.1111/j.1467-2494.2007.00368.x.

23. Rose $C$, Mandal AB. The interaction of sodium dodecyl sulfate and urea with cat-fish collagen solutions in acetate buffer: hydrodynamic and thermodynamic studies. Int J Biol Macromol. 1996:18(1-2):41-53. https://doi. org/10.1016/0141-8130(95)01054-8.
24. Santos SF, Zanette D, Fischer H, Itri R. A systematic study of bovine serum albumin (BSA) and sodium dodecyl sulfate (SDS) interactions by surface tension and small angle X-ray scattering. J Colloid Interface Sci. 2003;262(2): 400-8. https://doi.org/10.1016/s0021-9797(03)00109-7.

25. Moren AK, Regev O, Khan A. A Cryo-TEM study of protein-surfactant gels and solutions. J Colloid Interface Sci. 2000;222(2):170-8. https://doi.org/10.1 006/jcis.1999.6570.

26. He LR, Cai SM, Wu B, Mu C, Zhang G, Lin W. Trivalent chromium and aluminum affect the thermostability and conformation of collagen very differently. J Inorg Biochem. 2012;117:124-30. https://doi.org/10.1016/j. jinorgbio.2012.08.017.

27. Sma D, Mrr B, Ag C, et al. Physicochemical and conformational studies on interaction of myoglobin with an amino-acid based anionic surfactant, sodium N-dodecanoyl sarcosinate (SDDS). Colloid Surf A-Physicochem Eng Asp. 2019:577:167-74. https://doi.org/10.1016/j.colsurfa.2019.05.061.

28. He LR, Mu CD, Li DF, Lin W. Revisit the pre-transition of type I collagen denaturation in dilute solution by ultrasensitive differential scanning calorimetry. Thermochim Acta. 2012;548:1-5. https://doi.org/10.1016/j.tca.2 012.08.024.

29. Ghosh SJC, Biointerfaces SB. Conformational study of papain in the presence of sodium dodecyl sulfate in aqueous medium. Colloid Surf B-Biointerfaces. 2005; 41(2-3):209-16. https://doi.org/10.1016/j.colsurfb.2004.12.004

30. Mu CD, Li DF, Lin W, Ding Y, Zhang G. Temperature induced denaturation of collagen in acidic solution. Biopolymers. 2007;86(4):282-7. https://doi. org/10.1002/bip.20742.

31. Privalov PL, Tiktopulo El. Thermal conformational transformation of tropocollagen. I. Calorimetric study. Biopolymers. 1970;9(2):127-39. https:// doi.org/10.1002/bip.1970.360090202.

32. Maldonado FOA, Almeda M. Surfactants adsorption on collagen and chrome leather. Przeglad Skorzany (Leather Review). 1991;46:256-68.

33. Schrooyen PMM, Dijkstra PJ, Oberthur RC, et al. Stabilization of solutions of feather keratins by sodium dodecyl sulfate. J Colloid Interface Sci. 2001; 240(1):30-9. https://doi.org/10.1006/jcis.2001.7673.

34. Miller R, Alahverdjieva VS, Fainerman VB. Thermodynamics and rheology of mixed protein-surfactant adsorption layers. Soft Matter. 2008;4(6):1141-6. https://doi.org/10.1039/b802034e.

35. Cooper A. Heat capacity of hydrogen-bonded networks: an alternative view of protein folding thermodynamics. Biophys Chem. 2000;85(1):25-39. https://doi.org/10.1016/s0301-4622(00)00136-8.

36. KomsaPenkova R, Koynova R, Kostov G, et al. Thermal stability of calf skin collagen type I in salt solutions. BBA-Prot Struct Mol Enzymol. 1996;1297(2): 171-81. https://doi.org/10.1016/s0167-4838(96)00092-1.

37. Mertz EL, Leikin S. Interactions of inorganic phosphate and sulfate anions with collagen. Biochemistry. 2004;43(47):14901-12. https://doi.org/10.1021/ bi048788b.

38. Persikov AV, Ramshaw JAM, Kirkpatrick A, Brodsky B. Peptide investigations of pairwise interactions in the collagen triple-helix. J Mol Biol. 2002;316(2): 385-94. https://doi.org/10.1006/jmbi.2001.5342.

39. Lundahl P, Greijer E, Sandberg M, Cardell S, Eriksson KO. A model for ionic and hydrophobic interactions and hydrogen-bonding in sodium dodecylsulfate protein complexes. Biochim Biophys Acta. 1986;873(1):20-6. https:// doi.org/10.1016/0167-4838(86)90184-6.

40. Sun $Y$, Zhang JT, Wang HB, Wang $T$, Cheng $H$, Yu B, et al. Sulfate dodecyl sodium-induced stability of a model intrinsically disordered protein, bovine casein. Food Hydrocoll. 2018;82:19-28. https://doi.org/10.1016/j.foodhyd.201 8.03.043.

41. Giroux HJ, Britten M. Heat treatment of whey proteins in the presence of anionic surfactants. Food Hydrocoll. 2004;18(4):685-92. https://doi.org/10.1 016/j.foodhyd.2003.11.012.

\section{Publisher's Note}

Springer Nature remains neutral with regard to jurisdictional claims in published maps and institutional affiliations. 